\title{
Consistency and inconsistency in multispecies population network dynamics of coral reef ecosystems
}

\author{
Daniel M. Holstein ${ }^{1}$, Claire B. Paris ${ }^{2, *}$, Peter J. Mumby ${ }^{3}$ \\ ${ }^{1}$ Marine Biology and Fisheries, and ${ }^{2}$ Applied Marine Physics, Rosenstiel School of Marine and Atmospheric Science, \\ University of Miami, 4600 Rickenbacker Causeway, Miami, Florida 33149, USA \\ ${ }^{3}$ Marine Spatial Ecology lab, School of Biological Sciences, University of Queensland, St. Lucia, Queensland 4072, Australia
}

ABSTRACT: Different marine species and their larvae have characteristics that can expand or contract their potential dispersal, which can add complexity to the management of species assemblages. Here we used a multi-scale biophysical modeling framework, the Connectivity Modeling System, for the analysis of network connectivity for 5 Caribbean coral reef-associated species in order to gauge similarities and dissimilarities among species as well as among Caribbean regions. We estimated local dispersal and retention to assess regional exchanges, and our results revealed that the population structures of coral and fish are different and should thus have dissimilar management requirements in many regions, with some notable exceptions. Populations of Porites astreoides corals appear fragmented, suggesting that loss of adult colonies in any region may significantly impact regional recruitment success and connectivity. At the other end of the spectrum, populations of bluehead wrasse Thalassoma bifasciatum are highly connected, and removal of adults in any single region would not imply future recruitment failure in that region. We suggest using a 'diversity of exogenous settlement' index as a proxy of recolonization potential, which is related to the stability of regional connectivity networks. We demonstrate that resolving multispecies larval transport dynamics helps identify regions of both network stability for multi-generational connectivity (e.g. stable larval sources and corridors) pertinent to regionallevel management and network inconsistencies among species which are pertinent to the success of local management.

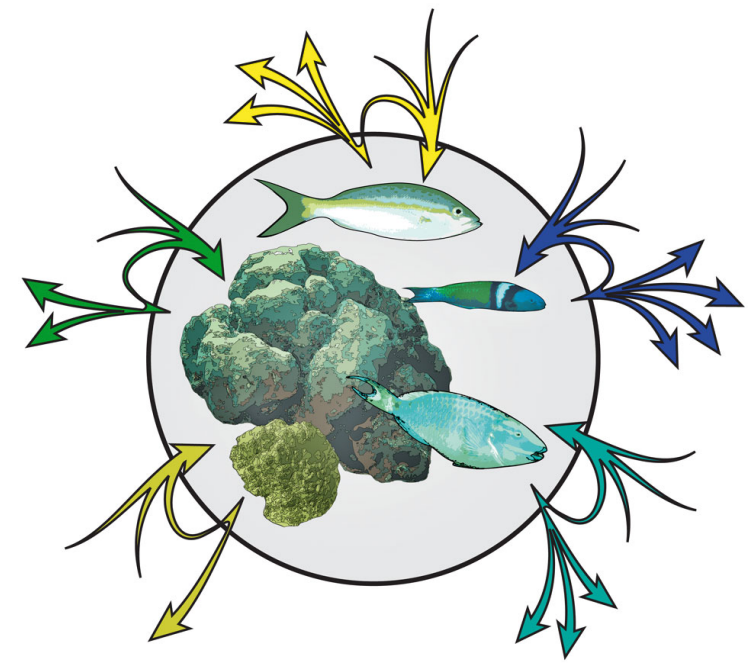

Constituent species of coral reef communities have different dispersal potentials and connectivity networks, which suggests that their populations will react uniquely to perturbation or conservation actions.

Image: Daniel Holstein

KEY WORDS: Connectivity $\cdot$ Larval dispersal $\cdot$ Sourcesink dynamics · Marine reserves · MPA · Ecological modeling $\cdot$ Coral reef resilience $\cdot$ Habitat fragmentation

Resale or republication not permitted without written consent of the publisher

\section{INTRODUCTION}

Understanding the dispersal dynamics of pelagic larvae in the oceans and how those dynamics affect the resilience, recovery, and management of marine 
resources continues to be a fundamental challenge at the forefront of marine ecology and policy (Sale et al. 2005). For many coral reef species, the pelagic larval phase is the only opportunity for migration, and import and export of larvae among connected populations is essential for metapopulation maintenance (Moilanen 1998, Hanski \& Ovaskainen 2000, Hanski 2003). Contrary to theoretical expectations (Largier 2003), larval dispersal direction and magnitude in real-world situations are often asymmetric and heterogeneous (Vuilleumier \& Possingham 2006, and citations therein). Adult sexual strategy (Paris et al. 2005), larval behavior (Leis \& McCormick 2002, Paris \& Cowen 2004), larval mortality (Cowen 2000, Vikebø et al. 2007), and persistent oceanographic features (Graham \& Largier 1997, Limouzy-Paris et al. 1997, Bassin et al. 2005, Sponaugle et al. 2005, Lipphardt et al. 2006) have all been shown to differentially affect recruitment and connectivity of marine larvae across the seascape.

For management purposes, reef areas are often described as either being a sink or a source of larval recruits. Sources are thought of as consistent suppliers of larvae, and sinks receive more recruits than they export. Resource managers, therefore, are often concerned with the sources of larvae coming into their managed areas, and productive larval sources are generally considered good candidates for protection because of their contributions to population resilience, particularly in areas that are harvested. The integration of larval connectivity into management planning is commonly considered advantageous (Cowen 2000, Gaines et al. 2003, Sale et al. 2005, Christie et al. 2010). However, as ubiquitous as these concepts are in the scientific and management communities, very little empirical evidence exists describing source-sink dynamics because evidence of larval connectivity can be difficult to acquire.

Multispecies ecosystem-based management is a robust management approach when attempting to maintain ecosystem services and functional redundancy (Gislason et al. 2000, Pauly et al. 2002, Browman \& Stergiou 2004). However, this approach is complicated by the fact that different marine species and their larvae have traits and behaviors that may expand or contract their potential dispersal capabilities. In an ideal world, management would benefit from simultaneous consideration of the dispersal abilities of every species of management concern. Some species might be selected because of their direct commercial importance to fisheries (Harrison et al. 2012), whereas others might facilitate production and biodiversity because of their role as ecosys- tem engineers, such as macroalgae and corals (Bozec et al. 2013). Here we estimate the source-sink dynamics of 5 diverse Caribbean coral reef-associated species in order to identify regions of potential importance to metacommunity persistence and management consideration. The persistence of a population can be defined as its replacement over space and time through all possible larval exchange pathways over multiple generations (Botsford et al. 2009). The simplest kind of replacement consists of larvae returning to their natal population (i.e. local retention, sensu Paris \& Cowen 2004); a more complex example might include larval pathways that connect populations through multiple generations, such as through corridors or stepping stones (Rozenfeld et al. 2008, Treml et al. 2008, Treml \& Halpin 2012). Here we investigated differential network dynamics among study species from local-scale larval exchanges to regional-scale connectivity and characterize consistent and inconsistent patterns of species-specific larval sources and sinks in the Caribbean.

\section{MATERIALS AND METHODS}

\section{Model initialization}

To investigate the network dynamics of larval dispersal in the Caribbean, we used a multi-scale biophysical model, the Connectivity Modeling System (CMS, Paris et al. 2013). The CMS simulated larval transport among populations and the larval flux between Caribbean regions over half a decade (2004 to 2008) for 3 species of coral reef fishes (the yellowtail snapper Ocyurus chrysurus, the stoplight parrotfish Sparisoma viride, and the bluehead wrasse Thalassoma bifasciatum) and 2 scleractinian corals (the boulder star coral Orbicella annularis, formerly Montastraea annularis, and the mustard hill coral Porites astreoides). O. chrysurus and $S$. viride are targeted for harvesting in many Caribbean fisheries, and T. bifasciatum is a model species with a plastic pelagic larval duration (PLD) (Swearer et al. 1999, Swearer 2001, Sponaugle et al. 2006, Hamilton et al. 2008, Munday et al. 2009) and has been the subject of genetic population studies (Purcell et al. 2006, Puebla et al. 2012). The carbonate skeletons of scleractinian corals form the framework and habitat of coral reefs. Scleractinian corals use 2 major life history strategies: brooding and broadcast spawning. These alternative strategies have implications for the dispersal of planulae larvae, and so we include an example of each, the brooder P. astreoides and the broadcaster $O$. annularis. 
The CMS couples ocean current, GIS-based habitat, and biological modules. The biological module includes traits such as spawning frequency, PLD, larval ontogenetic vertical shifts, and mortality (Paris et al. 2007). To maximize accuracy in larval dispersion calculations, a hierarchy of coupled nested models was used, all based in the community code of the Hybrid Coordinate Ocean Model (HYCOM; Bleck 2002). Starting from the larger domain, these included the HYCOM-Global 1/12 degree horizontal resolution (ca. $7 \mathrm{~km}$ grid), the Gulf of Mexico GoM-HYCOM 1/25 degree horizontal resolution (ca. $4 \mathrm{~km}$ grid), and finally the Florida Keys FKeyS-HYCOM 1/100 degree horizontal resolution (ca. $900 \mathrm{~m}$ grid; Kourafalou \& Kang 2012). All 3 models used 20 vertical layers.

For this study 3202 coral reef habitat polygons $\left(8 \mathrm{~km}^{2}\right.$ each, 'nodes' in Table 1) were developed from Caribbean coral reef extent datasets (Millenium Coral Reef Mapping Project, Andrefouet et al. 2005; Reefs at Risk, Burke et al. 2011). These nodes had dual functions as spawning/larval release and settlement habitats of local populations. Habitat nodes were also sub-grouped a priori into 23 Caribbean regions based on previous connectivity studies (Cowen et al. 2006, Bustamente \& Paris 2008) to facilitate the description of Caribbean network dynamics at local versus regional scales. Regions ranged in size from containing roughly 22 to $3000 \mathrm{~km}^{2}$ of reef habitat and 16 to 703 coral reef nodes (Fig. 1). The CMS tracked larvae ('particles') and recorded their positions (Paris et al. 2013). If a particle passed over suitable settlement habitat, i.e. a habitat node, during its settlement competency window, that particle was considered to have settled to that node (Table 1). This study as- sumed homogenous productivity at each reef node and makes no reference to post-settlement effects on recruitment success.

Spawning and larval traits were used to scale the number of particles released. The total number of particles released was computed to saturate all possibilities of dispersal for a given competency period, mortality rate, and release frequency (Kough et al. 2013). Thus, species-specific differences in the number of particles released from each node are based on computational minimums, not on species-specific reproductive output. For the fish species, 100 simulated larvae were released from each node on the first of every month across all 5 yr (6000 particles node $^{-1}$ ). Simulated larvae were released for each coral species according to limited species-specific reproductive seasons. Porites astreoides is a brooding coral that releases competent larvae throughout spring and summer, with peaks of larval release focused around new moons from March through August (Szmant 1986, Chornesky \& Peters 1987, McGuire 1998). On new moons from March through August each year, 100 particles were released from each node (2500 particles node ${ }^{-1}$ ).

Orbicella annularis populations experience 1 to 2 mass spawning events per year in late summer, 6 to 8 d after full moons (Szmant 1986, 1991, Szmant et al. 1997). Depending on the calendar date of full moons in late summer, particles were released in 2 late summer months (August, September, or October) each year. In total, 500 particles were released from each node, each selected month, distributed over $5 \mathrm{~d}$ with peaks on the seventh night after full moon (5000 particles node ${ }^{-1}$ ).

Table 1. Terms and definitions used in the analysis of network connectivity for 5 Caribbean coral reef-associated species

\begin{tabular}{|c|c|}
\hline Term & Definition \\
\hline Settlement & $\begin{array}{l}\text { In this study, settlement occurs when a competent larva encounters suitable } \\
\text { habitat }\end{array}$ \\
\hline Self-recruitment & $\begin{array}{l}\text { In this study, because post-settlement survivorship is not addressed, self- } \\
\text { recruitment (at times, self-regional recruitment) is the proportion of total local } \\
\text { settlement attributed to locally produced larvae }\end{array}$ \\
\hline Node & A vertex in a graph that may represent reef habitat or a region \\
\hline Edge & A line or arc in a graph connecting 2 nodes that represents larval exchange \\
\hline Region & $\begin{array}{l}\text { A collection of habitat nodes, grouped for analyses pertinent to management and } \\
\text { demographic connectivity }\end{array}$ \\
\hline Shortest path length & $\begin{array}{l}\text { The minimum number of node-to-node steps required to connect any } 2 \text { nodes, } i \\
\text { and } j\end{array}$ \\
\hline Longest shortest path & The longest shortest path length in a network \\
\hline Average shortest path & The mean shortest path length in a network (also median shortest path) \\
\hline Strongly connected component (SCC) & $\begin{array}{l}\text { A directed subgraph where all nodes are connected in both directions, albeit } \\
\text { possibly through multistep pathways }\end{array}$ \\
\hline Betweenness centrality (BC) & A measure of the importance of a node in connecting other nodes in the network \\
\hline
\end{tabular}




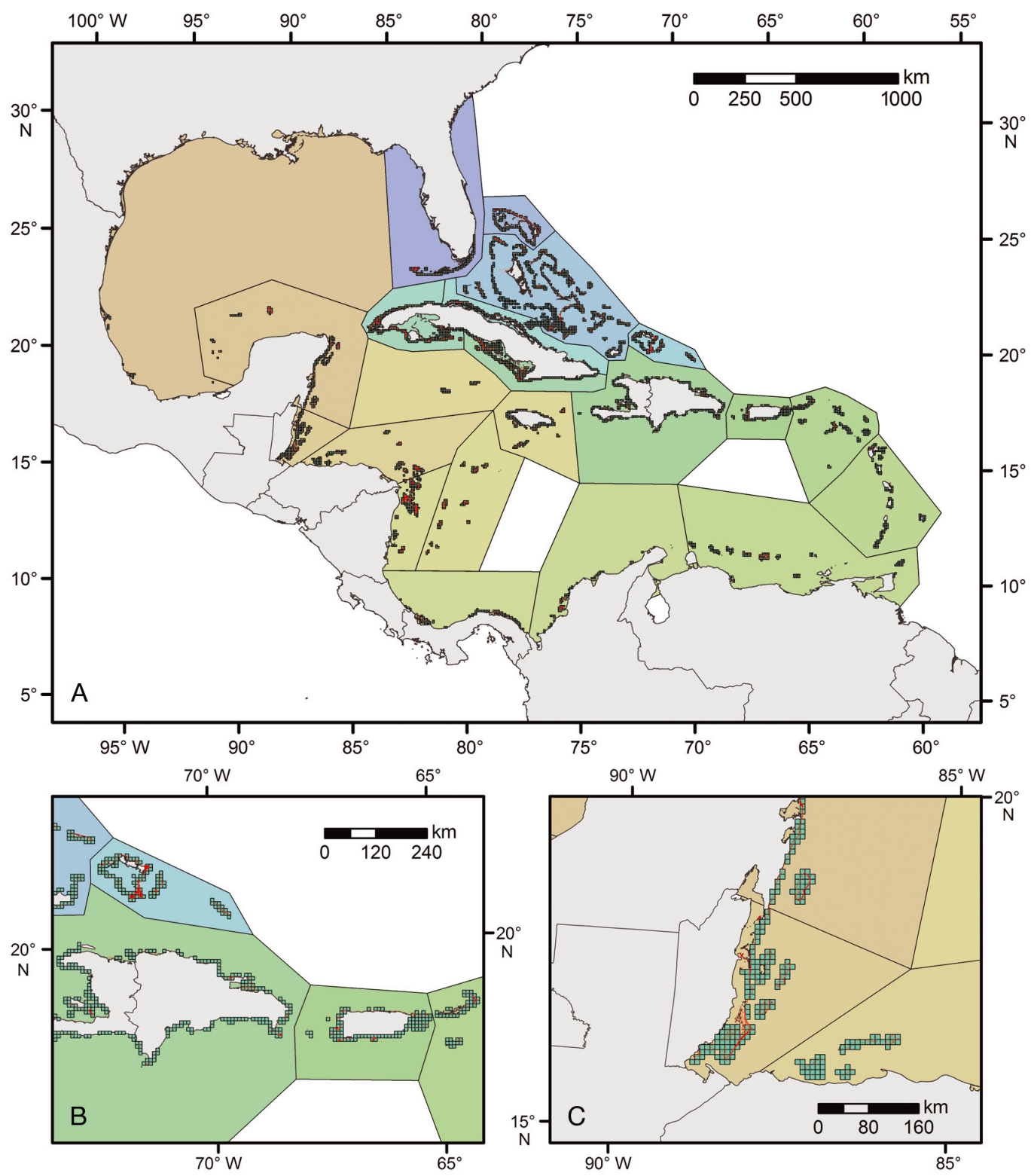

Fig. 1. Spatial representation of coral reef extent, polygons, and regions. We developed 3202 habitat nodes (each 8 km² ${ }^{2}$ green) for the Caribbean from coral reef extent datasets (red). Larger colored polygons represent 23 a priori Caribbean regions. (A)

Caribbean-wide. (B) Hispaniola, Puerto Rico, Turks and Caicos. (C) Belize. Colors of regions are used for clarity only

Species-specific larval behavior parameters were used for each fish and coral species, including time from release to competency, maximum PLD, flexion ages (for fish), vertical distributions, and mortality rates (Table 2). Mortality rates were calculated a priori as larval half-lives, such that approximately $50 \%$ of unsettled larvae would be surviving after half the maximum PLD.

For each species, the model generated transition matrices of $M$ dimension $(3202 \times 3202)$ with element $M_{i j}$ representing the number of particles originating at any node $i$ that migrate to any other node $j$ over the
5 yr simulation time. Without information on spawning production and the size of the population, the magnitude of larval fluxes cannot be realistically quantified. Yet, we can accurately quantify the probability of migration, $\breve{M}$, which was used in connectivity network analyses. Probabilities of migration $\breve{M}$ are calculated by normalizing the transition matrix $M$ (i.e. number of surviving particles in each node $M_{i j}$ ) by the total arrival from node $i$ :

$$
\breve{M}=\frac{M_{i j}}{\Sigma_{i} M_{i j}}
$$


Table 2. Species parameters and proportional settlement (ignoring any post-settlement mortality). Flexion determines the age at which major ontogenetic shifts occur in these fish species, including changes in mean depth of larvae (Paris \& Cowen 2004). Fish larvae were released on the first day of every month each year. Coral larvae were released according to restricted reproductive seasons and spawning events. 'Total larvae released' is over the $5 \mathrm{yr}$ simulation time. Note that higher proportional settlement in corals is due to a short time to competency. PLD: pelagic larval duration; na: not applicable

\begin{tabular}{|lcccccc|}
\hline Species & $\begin{array}{c}\text { Time to } \\
\text { competency (d) }\end{array}$ & $\begin{array}{c}\text { Maximum } \\
\text { PLD (d) }\end{array}$ & $\begin{array}{c}\text { Flexion } \\
\text { age (d) }\end{array}$ & $\begin{array}{c}\text { Release } \\
\text { frequency }\end{array}$ & $\begin{array}{c}\text { Total larvae } \\
\text { released (millions) }\end{array}$ & $\begin{array}{c}\text { Proportion of } \\
\text { larvae settled }\end{array}$ \\
\hline Thalassoma bifasciatum & 38 & 78 & 11 & Monthly & 18.89 & 0.18 \\
Ocyurus chrysurus & 25 & 47 & $11-18$ & Monthly & 18.89 & 0.16 \\
Sparisoma viride & 34 & 51 & 7 & Monthly & 18.89 & 0.14 \\
Orbicella annularis & 6 & 30 & na & Seasonal & 16.01 & 0.40 \\
Porites astreoides & 2 & 7 & na & Seasonal & 9.61 & 0.38 \\
\hline
\end{tabular}

The matrix $\breve{M}$ ('connectivity matrix' sensu Cowen et al. 2006), does not reflect the relative magnitude of settlement among nodes, rather, it reflects the probability that a larva spawned from node $i$ settles successfully at another node $j$, thus connecting the population $i$ to $j$. Regional connectivity matrices $\breve{R}(23 \times$ 23) were similarly developed at the regional scale representing the probability of larval migration from any region $I$ to any other region $J$. In this case, all transitions from habitats within region $I\left(I_{i}\right)$ to habitats in region $J\left(J_{j}\right)$ were pooled prior to being normalized.

\section{Network analyses}

Graph theoretical network analyses were performed at both fine (3202 habitat nodes) and regional (23 regions) scales for each species. The degree of habitat and regional connectivity for each species was compared using several estimates for network diameter and fragmentation (see Table 1 for terms and definitions). The number and geographic extents of strongly connected components, or directed subgraphs, in the connectivity networks of each species were calculated to highlight well-connected subpopulations. A strongly connected component (SCC) is made up of a set of nodes that are connected through directed paths in both the source and sink direction, albeit potentially through multistep connections (Andrello et al. 2013). Few SCCs in a network suggest a high degree of connectivity and low fragmentation. Isolated habitat nodes in the finescale analysis, or nodes that exchange larvae in only 1 direction, represent their own SCC and were not included when enumerating SCCs.

A shortest path is the minimum number of steps required to connect 2 nodes in a network. If 2 nodes are directly connected, the shortest path is 1 step, whereas if 2 nodes are connected through a single intermediary node, the shortest path between those 2 nodes is 2 steps, etc. Longest and average shortest paths are descriptive network statistics that estimate the diameter, or level of connectivity, of a network (Albert \& Barabási 2002). The longest shortest path in a network is simply the number of node-to-node steps required to connect the most distantly connected nodes in the network, and a shorter longest shortest path generally correlates to a more highly connected network. It is possible to have a shortest path of infinity in the instance where 2 nodes are not connected in a particular direction. Here, path lengths of infinity were noted but not included in the calculation of longest shortest path. Distributions of shortest paths in a network are generally not uniform, and thus the average or median shortest path may be a more descriptive network diameter statistic, especially in networks with many nodes. Again, smaller average or median shortest paths generally correlate with higher network connectivity, and infinite shortest paths were noted but not included in the calculation of these statistics.

Betweenness centrality (BC) is a measure indicating the degree to which a node serves to connect other nodes in the network, such as a corridor or stepping stone to multistep, or in this case, multigenerational connectivity (Freeman 1977, Estrada \& Bodin 2008, Rozenfeld et al. 2008, Treml et al. 2008, Treml \& Halpin 2012, Andrello et al. 2013). BC counts the fraction of shortest paths between pairs of nodes that pass through node $i$ :

$$
\mathrm{BC}(i)=\Sigma_{s \neq i \neq t} \frac{\sigma_{s t}(i)}{\sigma_{s t}}
$$

where $\sigma_{s t}$ denotes the total number of shortest paths between nodes $s$ and $t$, and $\sigma_{s t}(i)$ denotes the number of those that pass through node $i$. BC can be thought 
of as a measure of the importance of a node in maintaining the structure of the network and has been used to identify critical patches for the maintenance of connectivity in complex landscapes (Estrada \& Bodin 2008). Each region's BC was calculated for each species based on the regional connectivity matrix $\breve{R}$. The matrix was reweighted by the probability of migration (1 - $\breve{R}_{I J}$ ignoring unrealized connections), and the results were normalized to the maximum value of $\mathrm{BC}$.

\section{Regional analyses}

We have many ways to visualize dynamic networks; however, extracting useful node-specific information can be difficult, particularly in large multispecies networks. Thus, conservation benefits from a generalization of network connectivity into demographically significant, manageable units (in this case, regions). Because fine-scale network analyses revealed species-specific network dynamics that preclude the use of SCCs as multispecies management units, regions were developed a priori from previous studies that outline Caribbean ecoregions ('regions' herein) important to species management (Cowen et al. 2006, Bustamente \& Paris 2008).

The following are analyses designed to communicate source-sink relationships within and among regions for multiple species. Mean regional sourcesink indices (SS) were calculated for each species as the positive or negative difference in larvae being exported from and larvae being imported to a region, divided by the sum of import and export for that species in that region:

$$
\mathrm{SS}=\frac{\left(K_{\mathrm{out}}-K_{\mathrm{in}}\right)}{\left(K_{\mathrm{out}}+K_{\mathrm{in}}\right)}
$$

where $K$ represents the successful settlement into or out of a region. A value of 0 would indicate that the region experiences nearly equal import and export of settling larvae. Negative index values indicate that a region receives (imports) more exogenous settlers than it produces, and thus the region is a net sink. Positive index values indicate that the region is a net source. Indices of higher magnitude (positive or negative) indicate larger discrepancies between import and export, and regions with high index values may represent strong or consistent sources or sinks.

The number of connections a node or region shares is often used as a measure of connectivity, and may be referred to as that node's degree. Nodes with high degree are more connected, which may have impli- cations for metapopulation management. However, in this model, connections have weights corresponding to migration probability $\left(\breve{M}_{i j}\right.$ or $\left.\breve{R}_{I J}\right)$, and thus it follows that the richness of connections (degree) may not provide as much ecological information as the diversity of connections. Source and sink connection diversity indices were calculated for each region using a modified Shannon's diversity index $\left(S^{\prime}\right)$ :

$$
S^{\prime}=-\sum_{i=1}^{C_{\mathrm{d}}} p_{i} \ln p_{i}
$$

where $C$ is equal to the number of connections ( $d$ represents direction, and denotes whether $C$ is the inor out-degree of the region), and $p_{i}$ is the probability that any given connection is to or from a region $i$.

This index takes take into account not only a region's degree, or connection richness but also the evenness of those connections. Regions with many sources providing near equal proportions of the region's total settlement will have higher index values, and regions for which inputs are low or highly uneven will have lower index values. The exponent of this index, $\mathrm{e}^{S^{\prime}}$, represents the true diversity of connections (Hill 1973, Jost 2006). The discussion here focuses on upstream (source) connections only, as upstream connection diversity may have direct implications for population resilience, adult replacement, and the probability of experiencing the 'rescue effect' (Brown \& Kodric-Brown 1977, Hanski 1982, Gotelli 1991).

\section{RESULTS}

Over 82 million simulated larvae (particles) were tracked over a 5 yr simulation time, resulting in over 25 million source-sink connections. The networks of all 3 fish species are strongly connected, with only 1 major SCC in each species' network (Fig. 2, Table 3). Although not necessarily comprised of the same exact set of habitat nodes, the geographic extents of the major fish SCCs cover most of the Caribbean and are nearly identical. The network of Orbicella annularis is more fragmented, with 4 major SCCs, and the network of Porites astreoides is highly fragmented and has 54 major SCCs (here SCCs are considered 'major' when they are comprised of more than 2 habitat nodes).

Each species' connectivity network ( $\breve{M}$ or $\breve{R})$ can be graphed using vertices and edges, where each vertex represents a habitat node or region and each edge represents a larval pathway. The networks of fish species are more highly connected than those of 

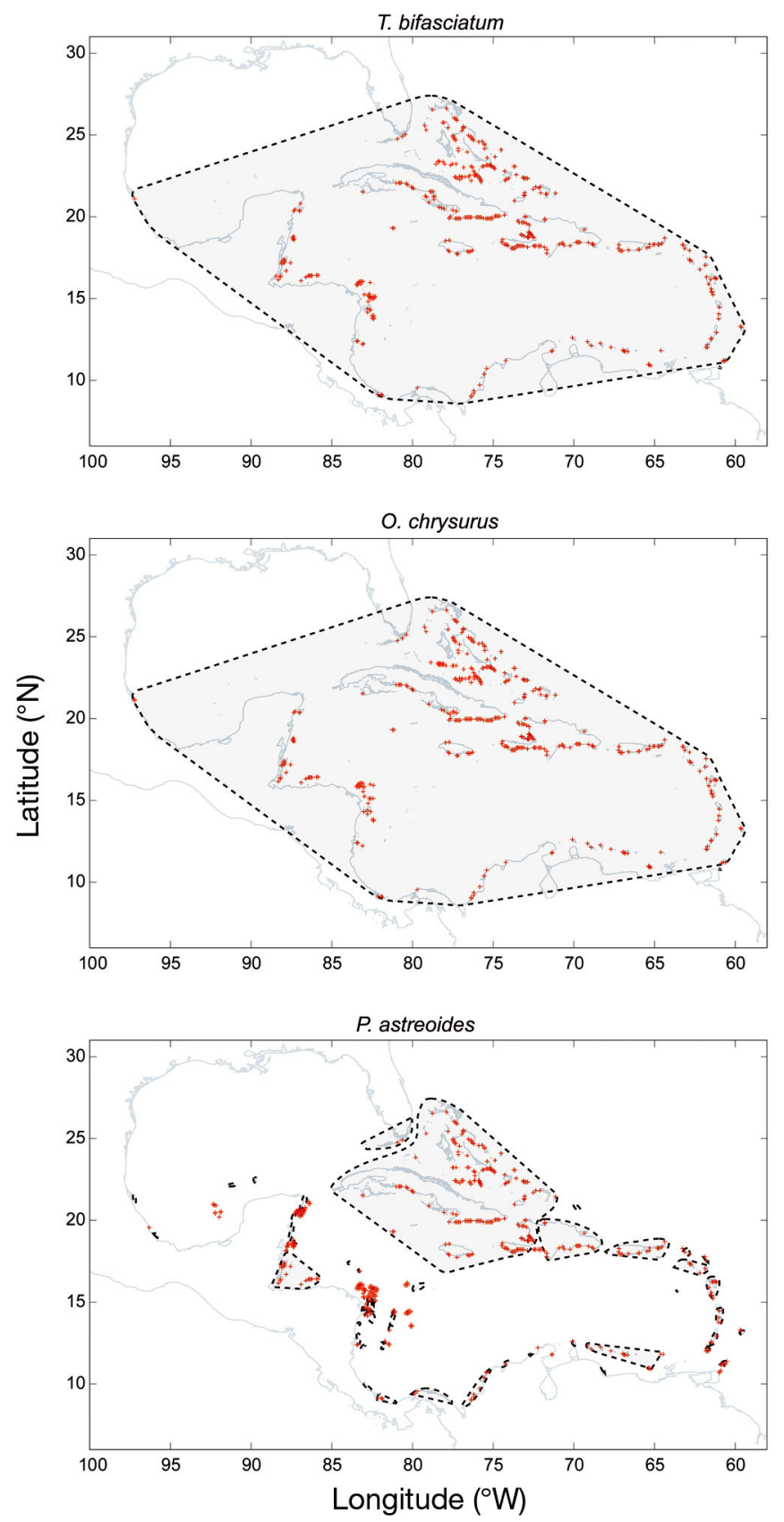

coral species, both at fine (Fig. 3) and regional (Fig. 4) scales (Table 3).

Comparisons of network diameter among species revealed similar trends at both fine and regional scales, namely that the network of Thalassoma bifasciatum is the most highly connected, and that network diameter is significantly greater in coral species (Fig. 5, Table 3). Ignoring isolated habitats, Porites astreoides populations are connected, on average, in about 13 generations, while fish populations are connected within 2 to 4 generations (Fig. 5, Table 3). The distribution of shortest paths at this scale was
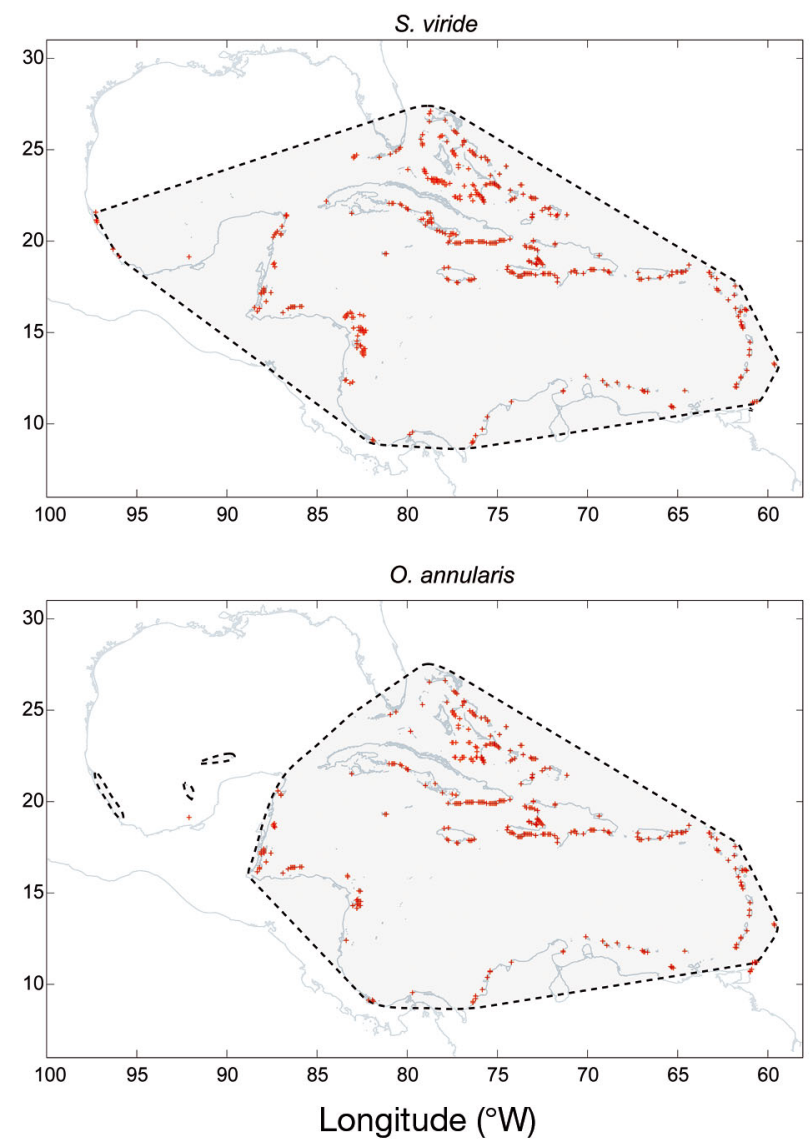

Fig. 2. Strongly connected components in the connectivity network of the 5 modeled species, using all 3202 habitat nodes. Gray polygons represent strongly connected components, and red points represent habitat nodes, or groups of 2 connected habitat nodes, that are isolated or only weakly connected to other components in the network. For fish species, there is 1 major strongly connected component in the Caribbean (technically, isolated habitats represent their own component; however, here they are ignored). There are 4 major strongly connected components in the connectivity network of Orbicella annularis. The connectivity network of Porites astreoides is highly fragmented, and there are many strongly connected components in the connectivity network of this species. See Table 2 for full species names

skewed, most dramatically so for the network of $P$. astreoides, which also had far more isolated nodes than the networks of the other species (Fig. 5). The network of $P$. astreoides is far more fragmented than that of any other species modeled. Not only are path lengths longer, but a large percentage of habitats would not be expected to exchange larvae, even over multiple generations, which could suggest high degrees of local adaptation. We found that the network of each species was significantly different in regards to median shortest paths at this scale (multiple comparison Kruskal-Wallis ANOVA, Bonferroni correc- 
Table 3. Graph theoretical estimates of network connectivity (diameter) for each species at both fine (3202 habitat nodes) and regional scale (23 regions). Diameter values are in 'steps' and suggest how many node-to-node steps are required to span the network. Lower numbers indicate higher network connectivity. In the fine-scale analysis, many habitats were isolated (Fig. 3); thus, unrealized connections with infinite path length are ignored for fine-scale network diameter estimates. All average shortest paths were significantly different from each other in the fine-scale analysis (multiple comparison Kruskal-Wallis ANOVA, Bonferroni correction, $\mathrm{p}<0.001$; Fig. 5A). At the regional scale, coral network diameter estimates result in infinity values because the network of Orbicella annularis is only weakly connected (the Gulf of Mexico represents its own strongly connected component), and the network of Porites astreoides is an unconnected graph. Shortest path comparisons were made ignoring infinite path lengths for the coral species. The networks of Thalassoma bifasciatum and Ocyurus chrysurus have similar longest shortest path lengths at the regional scale; however, $T$. bifasciatum's network has significantly shorter average shortest path lengths than all other species. The networks of $O$. chrysurus and Sparisoma viride have similar average shortest path lengths, as do the 2 coral species, which are significantly larger than the fish species (1-way ANOVA, Tukey's HSD, $\mathrm{p}<$ 0.001). Superscript letters indicate significantly different means within a column. SCC: strongly connected component

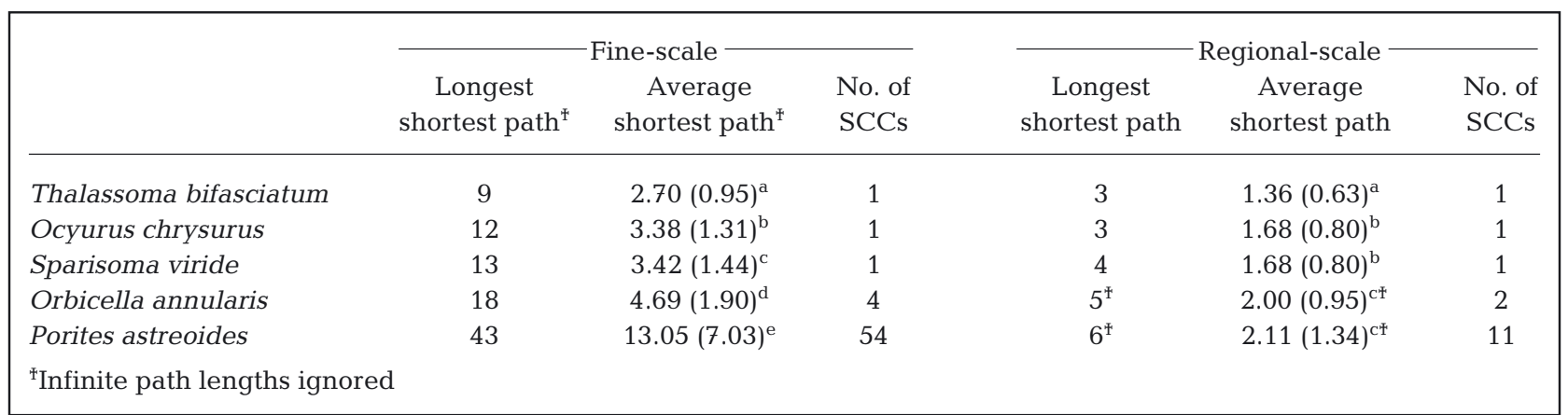

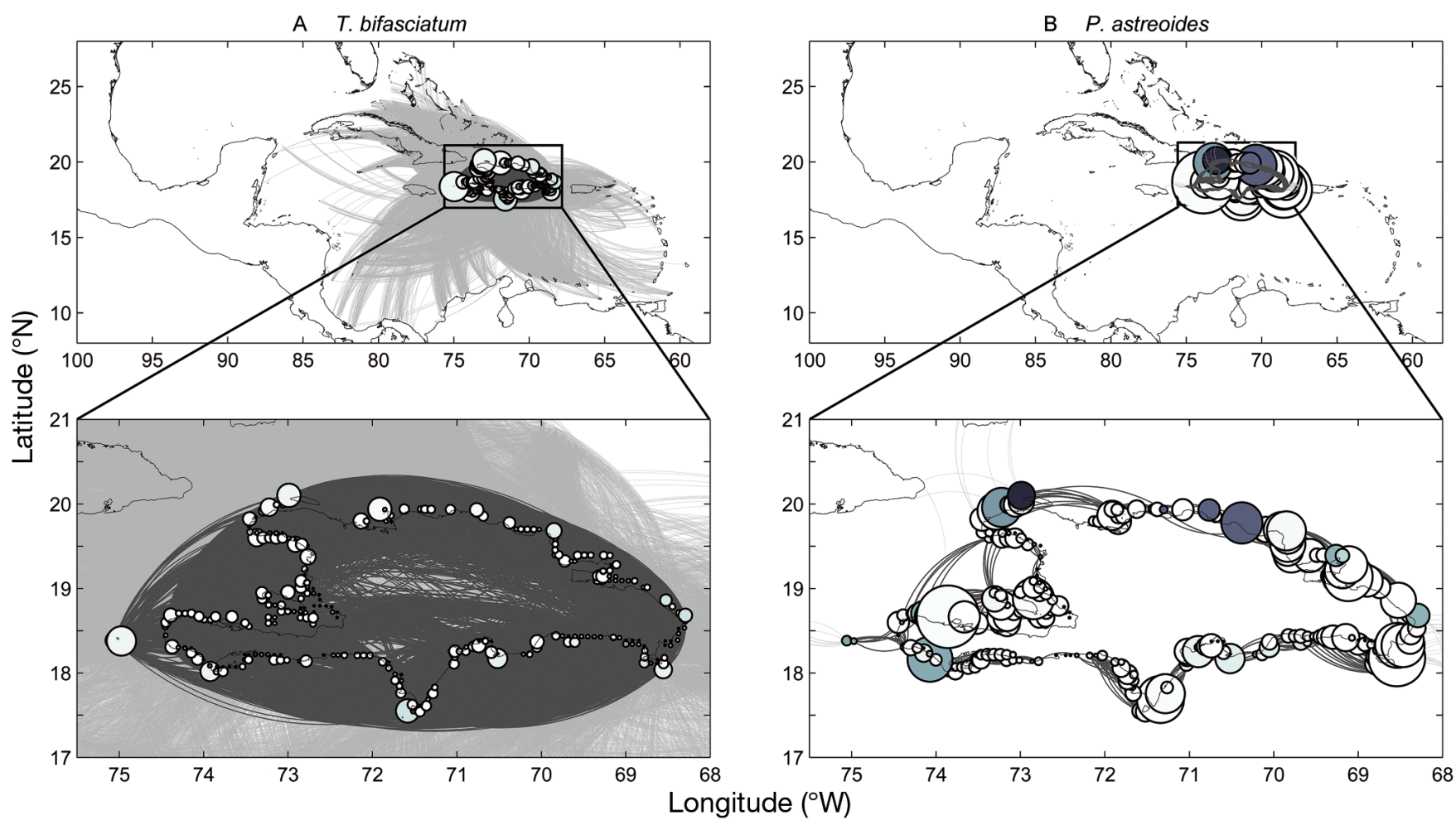

Fig. 3. Fine-scale connectivity within the Hispaniola region for both (A) Thalassoma bifasciatum and (B) Porites astreoides. Circles (vertices) represent habitat nodes; edges (arcs) represent larval exchange in the clockwise direction. Size of the vertex indicates the proportion of self-recruitment at that node; the shade of the vertex indicates the betweenness centrality (BC) of that habitat node (darker shades indicate higher values). Dark edges represent larval exchanges within the Hispaniola region; lighter edges represent larval exchanges between Hispaniola habitats and habitats outside of the region. Larval exchanges with a probability of arrival $<0.001$ are omitted for clarity and to illustrate connections with likely demographic significance. Note that in the case of $P$. astreoides, east and west Hispaniola belong to 2 separate strongly connected components (Fig. 2) 

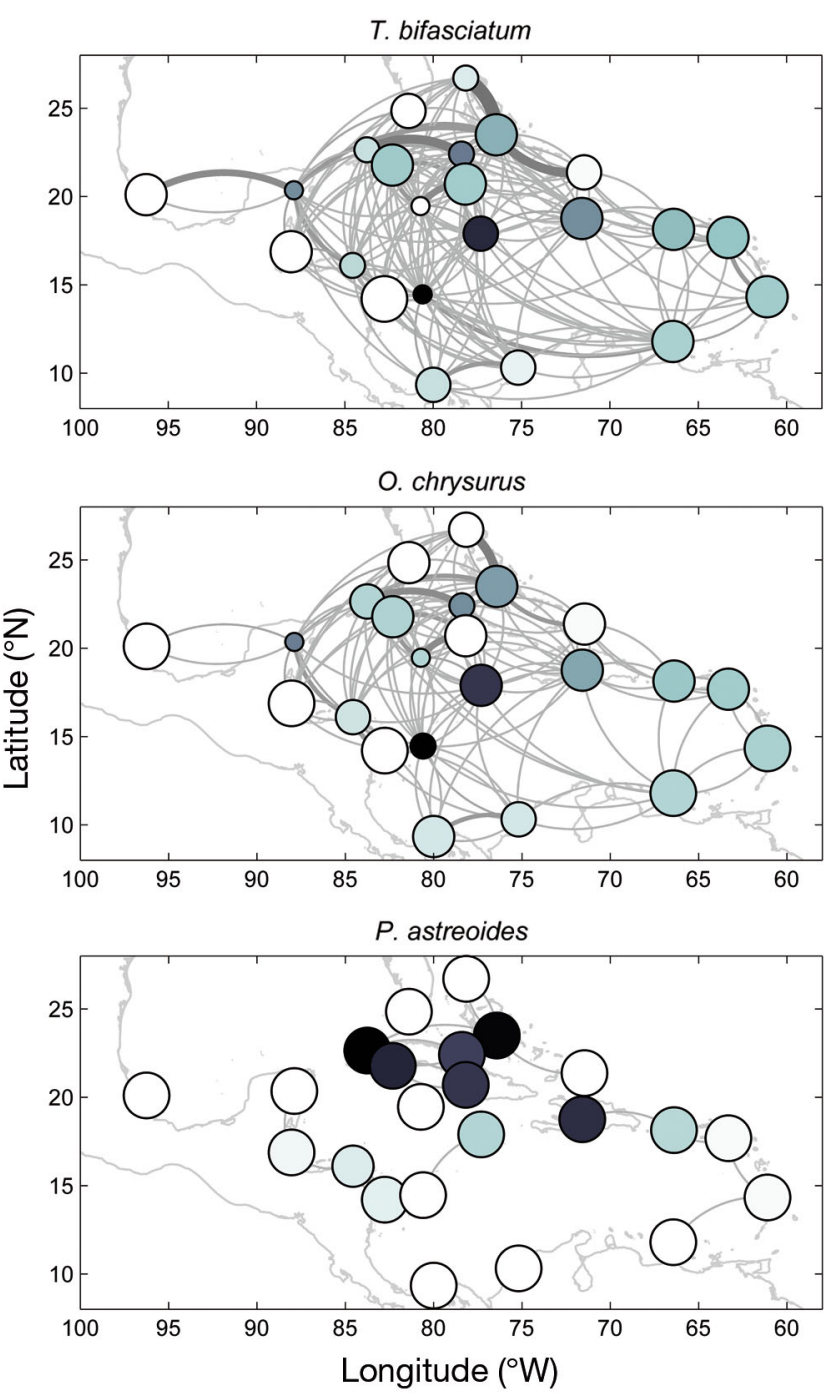

tion, $\mathrm{p}<0.001$; average shortest paths are shown in Table 3 for consistency). However, for the purposes of this study, non-integer differences in average shortest path between species - such as that between Ocyurus chrysurus $(3.38 \pm 1.31)$ and Sparisoma viride (3.42 \pm 1.44$)$ - may not be informative, as this value is used to estimate the number of generations required to span the network. Regional-scale analysis reduces the diameters of the connectivity networks, with the most dramatic reduction in $P$. astreoides (Table 3).

At the regional scale, the average shortest path for all 3 species is under 2 region-to-region steps, suggesting that, on average, every region has the potential to be connected in 2 steps or, in this model, in 2 generations. The network of Thalassoma bifasciatum has a significantly shorter average shortest path than any other modeled species (Table 3, 1-way ANOVA, Tukey's HSD, $\mathrm{p}<0.05$ ), indicating higher degrees of connectivity in comparison to the other 2 fish species or the coral species. The maximum PLD of $T$. bifascia-
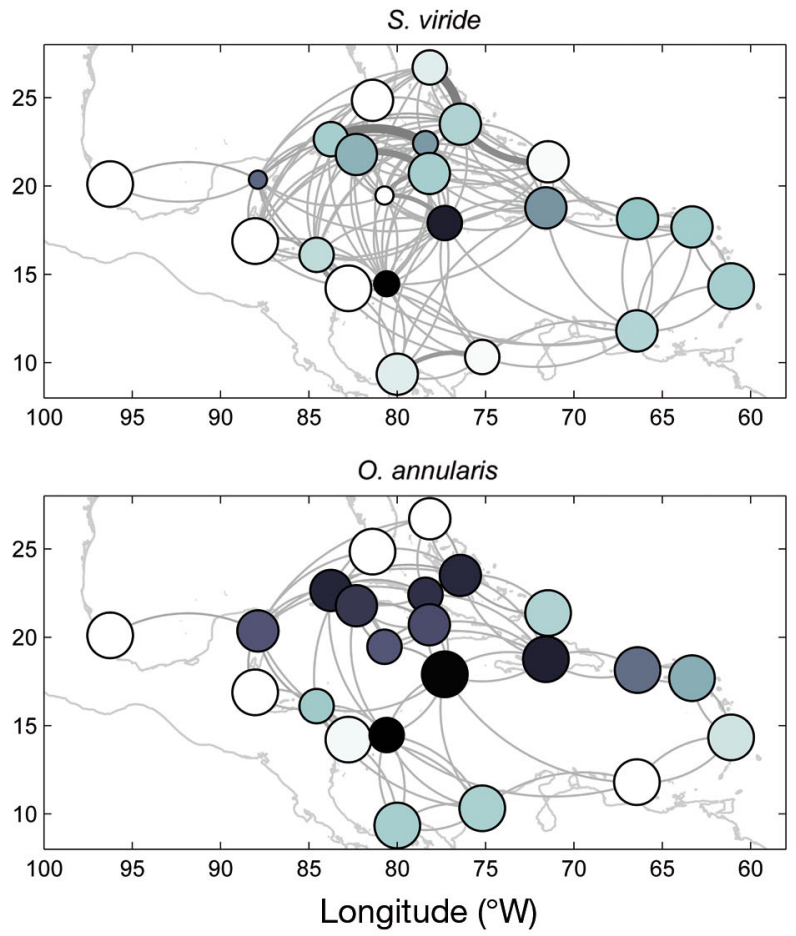

Fig. 4. Network graphs for the 5 studied species. Vertices represent regions; edges represent larval exchange (clockwise along arc). Size of the vertex indicates the proportion of self-regional recruitment; shade of the vertex indicates the betweenness centrality (BC) of that node (darker shades indicate higher values). The thickness of the edge represents probability of migration (threshold of 0.001 to illustrate connections of demographic significance). See Table 2 for full species names

tum is $53 \%$ greater than the parrotfish Sparisoma viride and is associated with a $19 \%$ increase in network connectivity (Table 3). The modeled PLDs of Ocyurus chrysurus and $S$. viride were similar with only a $7.8 \%$ difference, but their flexion ages were quite different at 11 to $18 \mathrm{~d}$ and $7 \mathrm{~d}$, respectively. Yet, despite differences in flexion ages and vertical distribution, the differences in network diameter were negligible at $<0.1 \%$ and not statistically significant (Table 3, 1-way ANOVA, Tukey's HSD, p > 0.05). All fish species demonstrate high probabilities of dispersal in the Bahamas and northeast Caribbean, as well as in the central Caribbean (Fig. 4).

The connectivity networks of the corals differ from those of the fish, as well as from each other. The network of the brooder Porites astreoides is highly fragmented, and self-recruitment is dominant in every region (Fig. 4). Of the 5 species modeled, $P$. astreoides is the only species that has an unconnected network at the regional scale, meaning that 

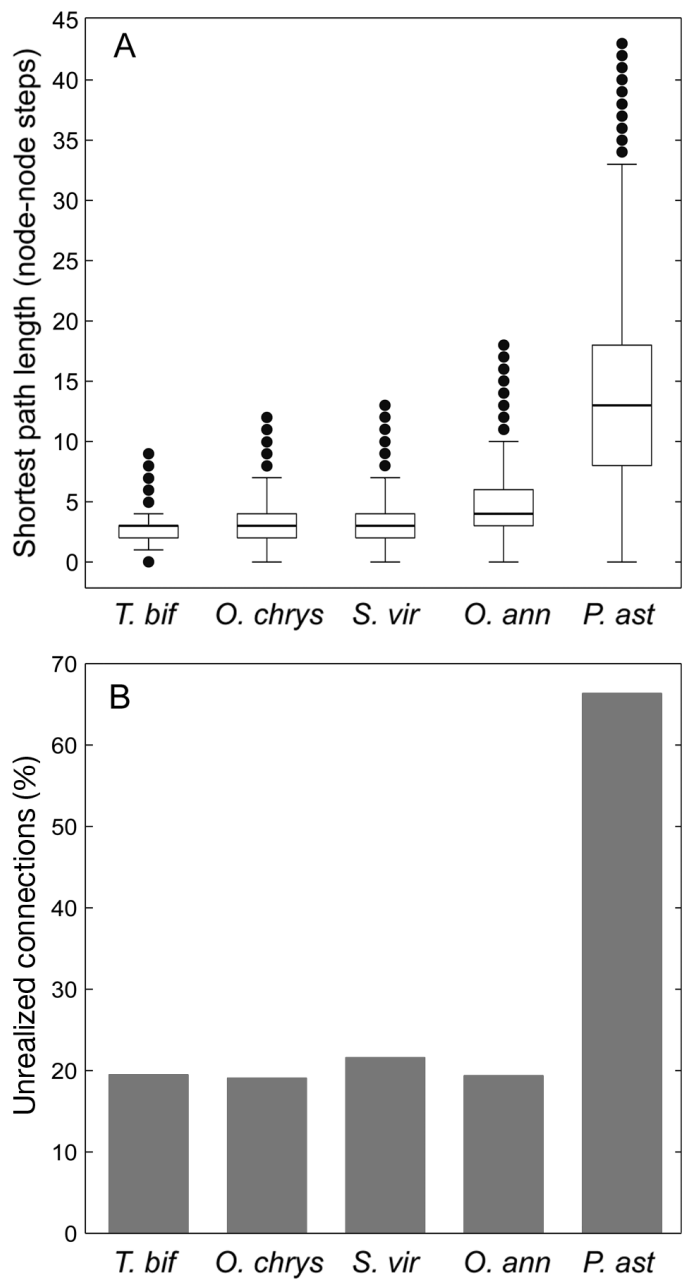

Fig. 5. (A) Shortest path lengths between all node-node pairs in the networks of each species, ignoring disconnected node pairs (which have infinite path length). Horizontal bars represent median shortest path lengths for the entirety of each network (the distributions of path lengths in each network failed Kolmogorov-Smirnov tests of normality, $\mathrm{p}<0.05$ ). Upper and lower edges of boxes represent the $25^{\text {th }}$ and $75^{\text {th }}$ percentiles; whiskers are the interquartile length multiplied by 1.5. Dots represent outliers. Median shortest paths are below 5 node-node steps in all networks except for that of the brooding coral Porites astreoides, which had a median shortest path length of 13, and maximum shortest path length of 43 , suggesting a much more fragmented network. The percentage of node-node pairs that were completely disconnected (node-node path length of infinity) is represented in

(B) for each species. See Table 2 for full species names

distinct metapopulations are confined to subgraphs in the network and might not exchange larvae in any direction. The spawning coral Orbicella annularis has a network intermediary to that of $P$. astreoides and the 3 fish species in terms of fragmentation and degree of connectivity. Although the graph is a connected graph, 1 region (Gulf of Mexico) does not receive larvae from any other region, meaning this graph is not strongly connected. The network of $O$. annularis has fewer connections than the fish species and the average shortest path is significantly longer than any fish species at both fine and regional scales (Table 3); however, at the regional scale $O$. annularis and $P$. astreoides have similar average shortest path lengths (Table 3, 1-way ANOVA, Tukey's HSD, p > 0.05). The maximum PLD of Thalassoma bifasciatum is $160 \%$ longer than that of $O$. annularis, and its network is $33 \%$ more connected.

Networks of fish species have similar patterns of regional $\mathrm{BC}$, with regions of high centrality in the central Caribbean, including Mexican reefs, Jamaica, and the Colombian Archipelago. Regions with low $\mathrm{BC}$ for fish include Belize, Nicaragua, Turks and Caicos, and the Florida reefs. Corals share a set of highly central regions unique from fish, including the Bahamas, Cuban reefs, and Hispaniola. The network of Orbicella annularis shares central regions with fish species as well, suggesting intermediate network dynamics between Porites astreoides and fish (Figs. 4 \& 6C). Regions with high centrality for all species include the Bahamas, north-central Cuba, and Hispaniola. Differences in $\mathrm{BC}$ among fish species exist in many regions despite similarities in maximum PLD and time to competency.

\section{Source-sink dynamics}

Of the 23 regions, 13 have species-specific mean SS indices, acting as a sink for some species and a source for others, including, for instance, the Colombian Archipelago and Honduras (Fig. 6A). Of those regions, 10 have similar index directions for all fish species, while 1 or both coral species has an opposite index direction. Mean SS index directions for fish species differ only in 3 regions: the Bahamas, which is a net source for Sparisoma viride and not the other 2 fish species; Venezuela, which is a net sink only for $S$. viride; and Honduras, which is a net source only for Thalassoma bifasciatum. The remaining 10-nearly half of all-regions show consistent mean index values in either the source or sink direction for all species. Consistent sources for all species include Turks and Caicos, northwest Cuba, southwest Cuba, the Nicaraguan Rise Islands, and Belize. Consistent sinks for all species include Florida reefs, north-central Cuba, southeast Cuba, the Gulf of Honduras (excluding T. bifasciatum), and Mexico.

Variability in mean SS index over the 5 yr studied is represented by standard deviation and can be seen in Fig. 6B. In general, coral species have higher vari- 


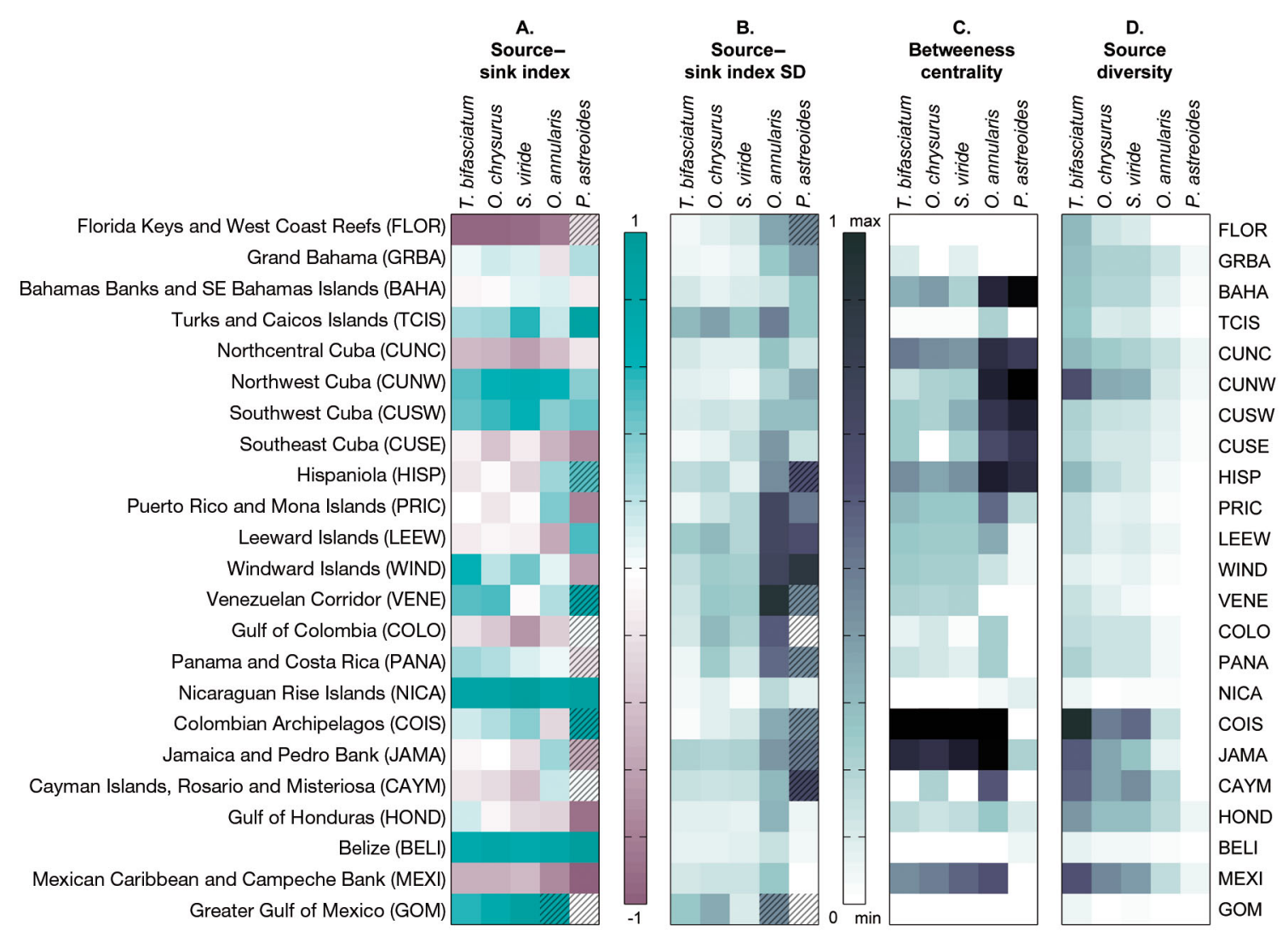

Fig. 6. (A) Mean source-sink (SS) indices by species for each region. Positive values indicate greater export than import (source), and negative values indicate greater import than export (sink). Values near 0 indicate near equal import and export. (B) SD of SS indices over the 5 yr modeling time. Hatched boxes represent nodes that have no connections in at least 1 direction in at least 1 year. (C) Relative betweenness centrality (BC) for each region and species. High values suggest importance for network stability and may indicate corridors for multigenerational connectivity. Note that corals and fish have distinct patterns of BC, and the network of Orbicella annularis shares attributes with fish in some regions. (D) Source diversity has implications for regional population persistence for each species. See Table 2 for full species names

ability in this index. Regions with index directions consistent across all species tend to have lower variability during the 5 yr study period, with a notable exception of the Turks and Caicos Islands. Similarly, high-magnitude mean SS index values by region and species are often associated with lower variability.

\section{Upstream connection diversity and isolation}

The proportion of self-regional recruitment is defined here as the proportion of settling larvae within each region that originated from reefs within that region. Although there is high variability, species with longer maximum PLDs and time to competency tend to have lower self-regional recruitment, and those regions tend to have a higher number of source connections. A decreasing linear relationship exists between the proportion of self-regional recruitment, and true diversity of upstream connec- tions ( $\mathrm{e}^{S^{\prime}} ;$ Fig. $\left.7 \mathrm{~B}, \mathrm{R}^{2}=.80, \mathrm{p}<0.001\right)$, suggesting that lower self-regional recruitment correlates with higher upstream connection diversity, and isolation correlates with a low diversity of larval inputs. Maximum $\mathrm{e}^{S^{\prime}}$ values decrease with maximum PLD and time to competency (Table 3, Fig. 7B, bounding boxes). Porites astreoides, the most isolated species in all regions, has probabilities of self-regional recruitment ranging from 0.87 to 1 in all regions. Regions in this species' network also have the fewest sources and lowest diversity of sources of all species (maximum $\mathrm{e}^{S^{\prime}}$ of 1.31). In contrast, regions in Thalassoma bifasciatum's network experience proportions of selfregional recruitment ranging from as low as 0.12 to 0.93 and $\mathrm{e}^{S^{\prime}}$ ranging from 1.28 to 6.11 , indicating considerable variability in the settlement dynamics of this species among regions (Figs. 6D \& 7).

For all species, south Cuba, Puerto Rico, the Windward Islands, Venezuela, Nicaragua, Belize, and the Gulf of Mexico experience high self-regional re- 

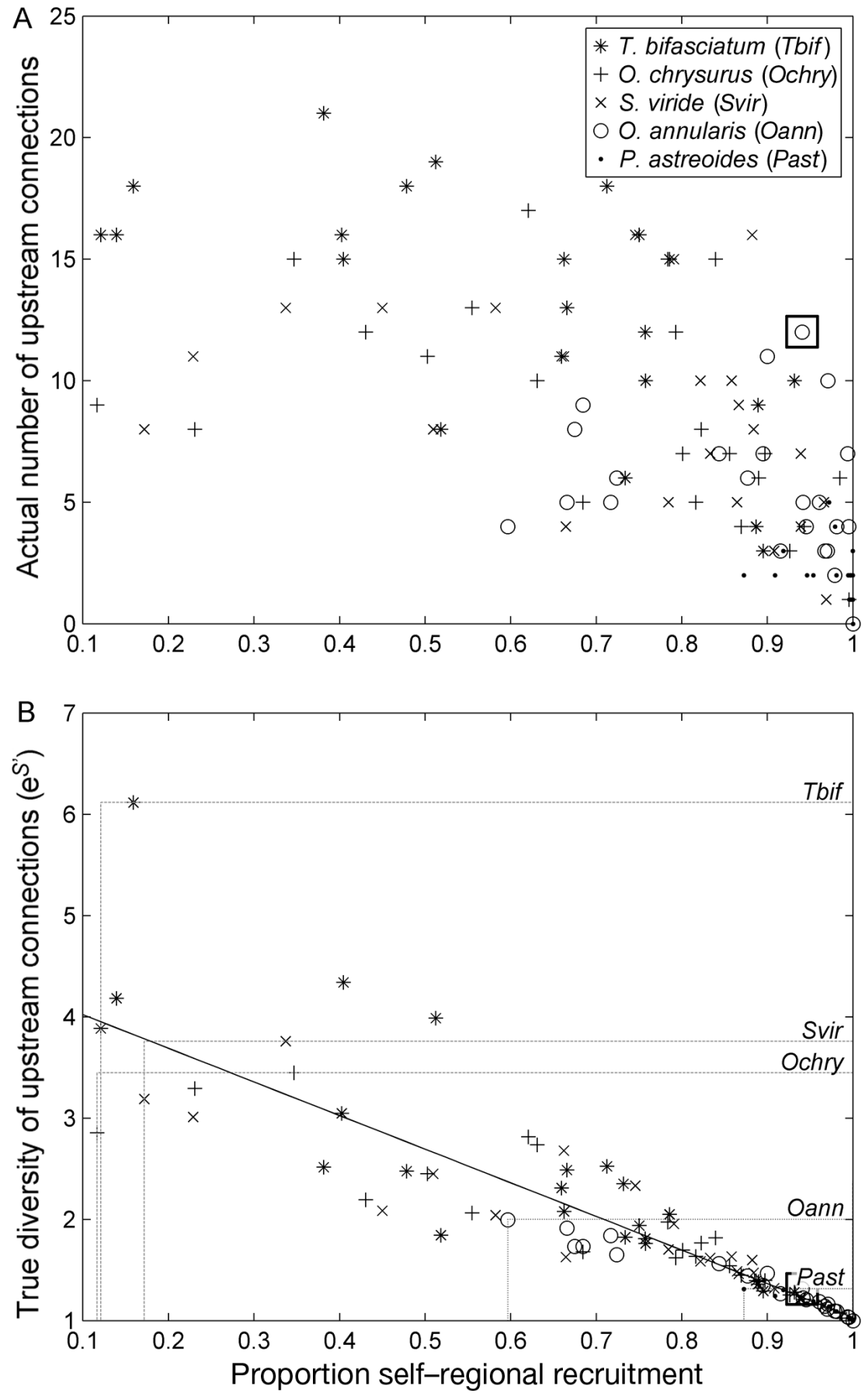

Fig. 7. (A) Number of upstream connections versus the proportion of selfregional recruitment for each species at each region. Regions are not explicitly labeled for clarity. (B) True diversity of upstream connections versus the proportion of self-regional recruitment for each species at each region. A linear relationship $\left(R^{2}=0.80, p<0.001\right)$ suggests that source diversity is negatively correlated with the proportion of self-regional recruitment. Dotted boxes indicate the lower threshold of self-regional recruitment and upper threshold of upstream connection diversity for each species. In (A) a box has been placed around the region of Jamaica in the network of Orbicella annularis to illustrate an instance where high upstream connection richness does not indicate high upstream connection diversity. See Table 2 for full species names cruitment and low upstream connection diversity. For fish species, settlement in north-central Cuba, the Colombian Archipelago, Cayman Islands, Honduras, and Mexico is primarily from exogenous upstream reefs, and the diversity of those upstream sources is high (Figs. 6D \& 7B, also see Jamaica and northwest Cuba). The same is true of northwest Cuba and Grand Bahama for Thalassoma bifasciatum.

\section{DISCUSSION}

\section{Effects of larval traits on connectivity}

Foster et al. (2012) demonstrated that larval exchange projections for Orbicella annularis made with the CMS (Paris et al. 2013) had a high degree of consensus with empirical genetic population data, with notable discrepancies likely due to habitat conditions not included in the model, such as low salinity runoff. We have expanded this model to include the larval exchange probabilities of 5 coral reef-associated species in order to gain insight into multispecies network dynamics. In doing so, we have shown that network dynamics are largely species-specific due to diverse reproductive and larval traits. Graph theoretic analyses of the connectivity networks of the 5 studied species statistically confirm some common assertions regarding maximum PLD and dispersive capabilities in marine organisms. Longer PLDs correspond with greater connectivity in this model; however, minimum PLD, or time to competency, appears to control local settlement dynamics and may have implications for habitat isolation and resilience. The fish species modeled have small network diameters of between 2 and 4 steps in the fine-scale analysis and less than 2 steps in the regional-scale analysis, which suggest that there is scope for significant geographic mixing over multiple generations. In the case of Thalassoma bifasciatum, this assertion is supported by 
population genetic studies that found no explicit spatial pattern to genetic variations in this fish in the Caribbean basin (Purcell et al. 2006, Puebla et al. 2012). T. bifasciatum has the longest maximum PLD of the modeled species together with deepest vertical migration, and its network is predicted to be richer in connections, have a smaller diameter (higher connectivity), and generally experience lower proportional self-regional recruitment and higher source diversity than the other 4 species. Correspondingly, the network of Porites astreoides, which has the shortest maximum PLD and time to competency of modeled species, also has the most fragmented network. This may corroborate findings by Puebla et al. (2012) that suggest that minimum and maximum PLD correlate with lower and upper confidence limits of estimates of dispersal distance based on genetic isolation in coral reef fish.

When comparing the similar connectivity networks of Sparisoma viride and Ocyurus chrysurus - which have comparable maximum PLDs but differing time to competency, flexion ages, and vertical distributions - the effects of non-PLD larval characteristics on connectivity are not statistically obvious using network diameter analyses, but can be seen as regional variations in settlement magnitude, which affect SS, $S^{\prime}$, and BC (Figs. $4 \& 6$ ). Due to larval behavior, the relationship between dispersal distance and PLD is non-linear (Shanks 2009), and shorter time to competency should increase the probability of settlement nearer to natal reefs, which increases the probability of self-recruitment. Flexion ages determine the timing of species-specific ontogenetic shifts in larval vertical distribution, which can expose pelagic larvae to horizontal and vertical flow velocities that may serve to retain or disperse larvae (Paris \& Cowen 2004), leading to species-specific network connectivity. Even for species with similar maximum PLD, such as $S$. viride and $O$. chrysurus, these differences in larval biology can create networks with regions that have functionally different roles and centralities. Although the networks of these 2 species appear similar, in many cases the removal of regions may have significantly different effects on multi-generational basin-scale connectivity.

$\mathrm{BC}$ is an estimate of the relative importance of a region in a network. There is high consistency in regional BC among fish species, and Orbicella annularis shares patterns of $\mathrm{BC}$ with fish species in the central Caribbean. This is likely due to overlap in maximum PLD, whereas the shorter larval duration of Porites astreoides restricts the connectivity of this species in the Colombian Archipelago and Jamaica
(Fig. 6C). The networks of coral species also share a set of highly central regions, including Bahamian reefs, Cuban regions, and Hispaniola. These regions behave as stepping stones to multigenerational connectivity for corals. Shorter time to competency restricts connectivity and enhances local retention, and connections with these highly central regions facilitate multigenerational connectivity in the more fragmented networks of coral species.

It is important to recognize that this study does not address any species-specific post-settlement mortality. Scaling connectivity by post-settlement mortality would reduce connectivity for all species, especially those with high predicted post-settlement mortality, such as Orbicella annularis (Hughes \& Tanner 2000, Edmunds \& Elahi 2007). However, the shapes of each species' connectivity network (Figs. $3 \& 4$ ) and the regional centralities within those networks would likely not change significantly if connectivity were scaled by spatially homogenous species-specific mortality rates. In reality, it is possible that post-settlement mortality - as well as larval production - is not homogenous over space, which could change the connectivity relationships both within and between regions. Additionally, it is possible that larvae settling at different times within their competency period have differential recruitment success, which could also alter the connectivity network.

\section{Source-sink dynamics}

The Bahamas, Venezuela, and Honduras are the only regions in which fish SS indices may be in opposite directions. In all other regions, the magnitude of index values may differ, but fish species have similar source-sink dynamics, suggesting that the adult replacement dynamics in these regions may be similar. This is likely due to persistent current regimes and relatively similar larval characteristics among these species (as compared to the coral species).

The 2 coral species have very different larval traits, and thus the source-sink dynamics are considerably different for each species. Because these source-sink patterns are so different, it is expected that realworld recruitment patterns for these species would be quite different as well (Glynn \& Colley 2008).

Variability in source-sink dynamics is higher for corals than for fish throughout the 5 yr study period. The most obvious reason for this is that the limited spawning window for coral species exposes settling larvae to higher environmental variability from year to year, as opposed to fish which reproduce year- 
round in this model. In the case of Porites astreoides, low levels of larval exchange may also create variability in source-sink dynamics for this species. Both coral species have short time to competency, and the probability of self-regional recruitment is high in most cases. This may imply that larval exchange occurs in pulses determined by variability in hydrodynamics, leading to higher variability in source-sink dynamics.

In regions where mean $\mathrm{SS}$ indices are in the same direction for all species, variation in SS index values tends to be lower for all species. This is also true for regions and species with high magnitude index values. This may imply that the arrangement and orientation of these regions in the seascape, as well as consistent hydrodynamic and eddy features, may be more responsible for the source-sink dynamics at these regions than larval traits.

\section{Source diversity and isolation}

The number of upstream connections providing larvae to a region may not be the best indicator of levels of connectivity or population resilience. For example, in Jamaica, Orbicella annularis has 12 upstream connections, meaning that more than half of the regions in the Caribbean contribute to settlement there. However, the proportion of self-recruitment for this coral in Jamaica is higher than 0.94, suggesting that an overwhelming proportion of settlers come from Jamaica itself. Although upstream connections are rich (Fig. 7A), the diversity of those connections is low (Figs. 6D \& 7B). How demographically significant are those upstream connections? The connection diversity index $S^{\prime}$ provides a metric that describes both the richness and evenness of source connections, which has implications for the recovery potential of a region after perturbation; a region with diverse upstream connections should be less vulnerable to variability in larval supply or a reduction in local reproductive success. Alternatively, regions with high proportions of self-recruitment are potentially vulnerable to recruitment failure should local reproductive success decline, and such regions are potentially vulnerable to isolation due to network fragmentation. Self-regional recruitment and the diversity of source connections are strongly linearly correlated $\left(\mathrm{R}^{2}=0.80\right)$. Regions that rely less on locally produced larvae generally rely instead on diverse sets of sources. Populations that experience exogenous larval subsidies have increased recovery potential due to the 'rescue effect' (Brown \& Kodric-Brown
1977, Hanski 1982, Gotelli 1991). More diverse subsidies (higher $S^{\prime}$ ) should correlate to a higher probability of rescue.

In some cases, regions are isolated physically, or are enclaves, which results in a high proportion of self-regional recruitment and low source diversity for all species. Examples include the Gulf of Mexico, regions in the eastern Caribbean, and Nicaraguan reefs. Alternatively, species with short time to competency or short PLD may be isolated in regions that are otherwise well-connected physically. The ecological result is the same; isolation likely limits rescue potential (Hanski 2001). Regions at the other extreme that experience low proportions of self-recruitment rely heavily on exogenous source populations, and severe network variability or an inhospitable pelagic environment could cause recruitment failure while isolated regions may be less affected.

\section{Management implications}

The spatial scales of marine populations are of critical importance to effective management of marine populations and the development of protected areas (Palumbi 2004), as is the simultaneous management of multispecies communities (Gislason et al. 2000, Pauly et al. 2002, Browman \& Stergiou 2004, Palumbi et al. 2009). In this study, both a fine-scale, habitatspecific analysis, and a more generalized regional analysis were used to investigate species-specific network dynamics in the Caribbean and further develop useful measures for describing real-world network connectivity. Regions and species with similar network dynamics may benefit from similar management focuses. For example, populations with low self-recruitment and high source diversity may benefit most from the maintenance of upstream populations. Oppositely, regions and species that predominantly receive locally produced recruits may benefit most from the maintenance of local adult reproductive populations. Because there is evidence that coral recovery and recruitment can be enhanced through the rebuilding of fish biomass (Mumby \& Harborne 2010), the management of isolated coral populations may not be decoupled from that of the management of local and upstream fish populations.

Variability in connectivity and network characteristics, both among and within species, represents a challenge to successful multispecies management. Networks of marine protected areas arranged to incorporate dispersal kernel probabilities are considered ideal for the protection of marine species 
(Steneck et al. 2009); however, kernels vary with species and location, and the high degree of complexity of marine larval connectivity has not been fully integrated into marine protected area design. Here we propose that areas (reefs, countries, regions, etc.) that are important for multispecies connectivity and network stability should be a focus of marine protection. In the current study, several regions showed high BC for all or most species, including Hispaniola, north-central Cuba, and some smaller regions in the central Caribbean, such as the Colombian Archipelago and Jamaica. These regions are likely important for multi-generational connectivity for all modeled species, at least partly due to the physical location of these regions in the seascape. Preserving and maintaining suitable settlement and reproductive habitat at highly central regions may be critical to metapopulation maintenance. Areas that consistently provide larvae to downstream reefs, especially if they behave as sources for multispecies assemblages, are particularly valuable. Because marine reserves cannot protect organisms from major physical disturbances such as storms or bleaching events, management benefits from spreading risk across the seascape (Allison et al. 2003, Mumby et al. 2011), and the protection of regions that have natural resilience due to consistent and diverse larval inputs may represent good investments of resources.

Our study suggests that estimating diversity of exogenous settlement or recruitment may provide a proxy of recolonization potential. Multispecies network dynamics reveal stability (e.g. sources, corridors, and naturally resilient locations) pertinent to regional level management but also species-specific dissimilarities, which may demand local and speciesspecific management. In most cases, management will and should occur at scales finer than discussed here, but the analyses used are applicable at all spatial scales. Larval connectivity models and network theory will continue to contribute valuable information to the management and protection of marine habitats, especially as the potential for further reef fragmentation and other physical changes to the environment alter both the habitat and the biology of coral reef organisms and their larvae.

Acknowledgements. This study was funded by the Natural Environmental Research Council and EU FORCE project (to P.J.M. and C.B.P.) and an ARC Laureate Fellowship (P.J.M.). NSF-RAPID 1048697 (to C.B.P.) allowed the development of the Connectivity Modeling System. We thank M. Miller for constructive comments, and the reviewers for thorough feedback.

\section{LITERATURE CITED}

Albert R, Barabási AL (2002) Statistical mechanics of complex networks. Rev Mod Phys 74:47-97

Allison G, Gaines S, Lubchenco J, Possingham HP (2003) Ensuring persistence of marine reserves: Catastrophes require adopting an insurance factor. Ecol Appl 13:8-24

Andrefouet S, Muller-Karger FE, Robinson JA, Kranenburg CJ, Torres-Pulliza D, Spraggins SA, Murch B (2005) Global assessment of modern coral reef extent and diversity for regional science and management applications: a view from space. Proc 10th Int Coral Reef Symp, Okinawa, p 1732-1745

Andrello M, Mouillot D, Beuvier J, Albouy C, Thuiller W, Manel S (2013) Low connectivity between Mediterranean marine protected areas: a biophysical modeling approach for the dusky grouper Epinephelus marginatus. PLoS ONE 8:e68564

Bassin CJ, Washburn L, Brzezinski M, McPhee-Shaw E (2005) Sub-mesoscale coastal eddies observed by high frequency radar: a new mechanism for delivering nutrients to kelp forests in the Southern California Bight. Geophys Res Lett 32:L12604, doi:10.1029/2005GL023017

Bleck R (2002) An oceanic general circulation model framed in hybrid isopycnic-Cartesian coordinates. Ocean Model 4:55-88

Botsford LW, White JW, Coffroth Ma, Paris CB and others (2009) Connectivity and resilience of coral reef metapopulations in marine protected areas: matching empirical efforts to predictive needs. Coral Reefs 28:327-337

- Bozec YM, Yakob L, Bejarano S, Mumby PJ (2013) Reciprocal facilitation and non-linearity maintain habitat engineering on coral reefs. Oikos 122:428-440

Browman HI, Stergiou KI (2004) Marine Protected Areas as a central element of ecosystem-based management: defining their location, size and number. Mar Ecol Prog Ser 274:271-272

> Brown J, Kodric-Brown A (1977) Turnover rates in insular biogeography: effect of immigration on extinction. Ecology 58:445-449

Burke L, Reytar K, Spalding M, Perry A (2011) Reefs at risk revisited. World Resources Institute, Washington, DC

Bustamente G, Paris C (2008) World Heritage Sites and marine population connectivity. In: Grober-Dunsmore R, Keller B (eds) Caribbean connectivity: implications for marine protected area management. NMSP-08-07. US Department of Commerce, NOAA, National Marine Sanctuary Program, Silver Spring, MD, p 102-117

Chornesky E, Peters E (1987) Sexual reproduction and colony growth in the scleractinian coral Porites astreoides. Biol Bull (Woods Hole) 172:161-177

Christie MR, Johnson DW, Stallings CD, Hixon MA (2010) Self-recruitment and sweepstakes reproduction amid extensive gene flow in a coral-reef fish. Mol Ecol 19: 1042-1057

Clarke ME, Domeier ML, Laroche WA (1997) Development of larvae and juveniles of the mutton snapper (Lutjanus analis), lane snapper (Lutjanus synagris) and yellowtail snapper (Lutjanis chrysurus). Bull Mar Sci 61:511-537

> Cowen RK (2000) Connectivity of marine populations: open or closed? Science 287:857-859

Cowen RK (2002) Oceanographic influences on larval dispersal and retention and their consequences for population connectivity. In: Sale PF (ed) Coral reef fishes: dynamics and diversity in a complex ecosystem. Academic 
Press, London, p 149-170

Cowen RK, Paris CB, Srinivasan A (2006) Scaling of connectivity in marine populations. Science 311:522-527

Edmunds PJ, Elahi R (2007) The demographics of a 15-year decline in cover of the Caribbean reef coral Montastraea annularis. Ecol Monogr 77:3-18

Estrada E, Bodin Ö (2008) Using network centrality measures to manage landscape connectivity. Ecol Appl 18: 1810-1825

Foster NL, Paris CB, Kool JT, Baums IB and others (2012) Connectivity of Caribbean coral populations: complementary insights from empirical and modelled gene flow. Mol Ecol 21:1143-1157

Freeman LC (1977) A set of measures of centrality based on betweenness. Sociometry 40:35-41

Gaines SD, Gaylord B, Largier JL (2003) Avoiding current oversights in marine reserve design. Ecol Appl 13:32-46

> Gislason H, Sinclaire M, Sainsbury K, O'Boyle R (2000) Symposium overview: incorporating ecosystem objectives within fisheries management. ICES J Mar Sci 57:468-475

Gleason DF, Danilowicz BS, Nolan CJ (2009) Reef waters stimulate substratum exploration in planulae from brooding Caribbean corals. Coral Reefs 28:549-554

Glynn PW, Colley SB (2008) Survival of brooding and broadcasting reef corals following large scale disturbances : Is there any hope for broadcasting species during global warming? Proc 11th Int Coral Reef Symp, Ft Lauderdale, FL, p 361-365

Gotelli NJ (1991) Metapopulation models: the rescue effect, the propogule rain, and the core-satellite hypothesis. Am Nat 138:768-776

> Graham WM, Largier JL (1997) Upwelling shadows as nearshore retention sites: the example of northern Monterey Bay. Cont Shelf Res 17:509-532

Hamilton SL, Regetz J, Warner RR (2008) Postsettlement survival linked to larval life in a marine fish. Proc Natl Acad Sci USA 105:1561-1566

> Hanski I (1982) Dynamics of regional distribution: the core and satellite species hypothesis. Oikos 38:210-221

> Hanski I (2001) Spatially realistic theory of metapopulation ecology. Naturwissenschaften 88:372-381

Hanski I (2003) Metapopulation theory for fragmented landscapes. Theor Popul Biol 64:119-127

Hanski I, Ovaskainen O (2000) The metapopulation capacity of a fragmented landscape. Nature 404:755-758

> Harrison HB, Williamson DH, Evans RD, Almany GR and others (2012) Larval export from marine reserves and the recruitment benefit for fish and fisheries. Curr Biol 22: 1023-1028

> Hill MO (1973) Diversity and evenness: a unifying notation and its consequences. Ecology 54:427-432

Hughes TP, Tanner JE (2000) Recruitment failure, life histories, and long-term decline of Caribbean corals. Ecology 81:2250-2263

> Jost L (2006) Entropy and diversity. Oikos 113:363-375

Kough AS, Paris CB, Butler MJ (2013) Larval connectivity and the international management of fisheries. PLoS ONE 8:e64970

Kourafalou V, Kang H (2012) Florida Current meandering and evolution of cyclonic eddies along the Florida Keys Reef Tract: Are they interconnected? J Geophys Res 117: C05028, doi:10.1029/2011JC007383

> Largier JL (2003) Considerations in estimating larval dispersal distances from oceanographic data. Ecol Appl 13: 71-89
Leis JM, McCormick MI (2002) The biology, behavior and ecology of the pelagic larval stage of coral reef fishes. In: Sale PF (ed) Coral reef fishes: dynamics and diversity in a complex ecosystem. Academic Press, San Diego, CA, p 171-199

Limouzy-Paris CB, Graber HC, Jones DL, Ropke AW, Richards WJ (1997) Translocation of larval coral reef fishes via sub-mesoscale spin-off eddies from the Florida current. Bull Mar Sci 60:966-983

Lindeman KC (1997) Development of grunts and snappers of southeast Florida: cross-shelf distributions and effects of beach management alternatives. PhD dissertation, University of Miami, FL

Lindeman KC, Pugliese R, Waugh GT, Ault JS (2000) Developmental patterns within a multispecies reef fishery: management applications for essential fish habitats and protected areas. Bull Mar Sci 66:929-956

> Lipphardt BL, Small D, Kirwan D, Wiggins S, Ide K, Grosch CE, Paduan JD (2006) Synoptic Lagrangian maps: application to surface transport in Monterey Bay. J Mar Res 64:221-247

> Masterson CF, Danilowicz BS, Sale PF (1997) Yearly and inter-island variation in the recruitment dynamics of the bluehead wrasse (Thalassoma bifasciatum, Bloch). J Exp Mar Biol Ecol 214:149-166

McGuire MP (1998) Timing of larval release by Porites astreoides in the northern Florida Keys. Coral Reefs 17: 369-375

Moilanen A (1998) Metapopulation dynamics: effects of habitat quality and landscape structure. Ecology 79: 2503-2515

Mumby PJ, Harborne AR (2010) Marine reserves enhance the recovery of corals on Caribbean reefs. PLoS ONE 5: e8657

Mumby PJ, Vitolo R, Stephenson DB (2011) Temporal clustering of tropical cyclones and its ecosystem impacts. Proc Natl Acad Sci USA 108:17626-17630

> Munday PL, Leis JM, Lough JM, Paris CB, Kingsford MJ, Berumen ML, Lambrechts J (2009) Climate change and coral reef connectivity. Coral Reefs 28:379-395

- Palumbi SR (2004) Marine reserves and ocean neighborhoods: the spatial scale of marine populations and their management. Annu Rev Environ Resour 29:31-68

Palumbi SR, Sandifer PA, Allan JD, Beck MW and others (2009) Managing for ocean biodiversity to sustain marine ecosystem services. Front Ecol Environ 7:204-211

Paris CB, Cowen RK (2004) Direct evidence of a biophysical retention mechanism for coral reef fish larvae. Limnol Oceanogr 49:1964-1979

Paris CB, Cowen RK, Claro R, Lindeman KC (2005) Larval transport pathways from Cuban snapper (Lutjanidae) spawning aggregations based on biophysical modeling. Mar Ecol Prog Ser 296:93-106

Paris CB, Chérubin LM, Cowen RK (2007) Surfing, spinning, or diving from reef to reef: effects on population connectivity. Mar Ecol Prog Ser 347:285-300

Paris CB, Helgers J, van Sebille E, Srinivasan A (2013) Connectivity Modeling System: a probabilistic modeling tool for the multi-scale tracking of biotic and abiotic variability in the ocean. Environ Model Softw 42: $47-54$

Pauly D, Christensen V, Guénette S, Pitcher TJ and others (2002) Towards sustainability in world fisheries. Nature 418:689-695

> Puebla O, Bermingham E, McMillan WO (2012) On the 
spatial scale of dispersal in coral reef fishes. Mol Ecol 21: 5675-5688

Purcell JFH, Cowen RK, Hughes CR Williams DA (2006) Weak genetic structure indicates strong dispersal limits: a tale of two coral reef fish. Proc R Soc Lond B Biol Sci 273:1483-90

Robertson DR, Karg F, Leao de Moura R, Victor BC, Bernardi G (2006) Mechanisms of speciation and faunal enrichment in Atlantic parrotfishes. Mol Phylogenet Evol 40: 795-807

Rozenfeld AF, Arnaud-Haond S, Hernández-García E, Eguíluz VM, Serrão EA, Duarte CM (2008) Network analysis identifies weak and strong links in a metapopulation system. Proc Natl Acad Sci USA 105:18824-9

Sale PF, Cowen RK, Danilowicz BS, Jones GP and others (2005) Critical science gaps impede use of no-take fishery reserves. Trends Ecol Evol 20:74-80

Shanks AL (2009) Pelagic larval duration and dispersal distance revisited. Biol Bull (Woods Hole) 216:373-385

Sponaugle S, Lee T, Kourafalou V, Pinkard D (2005) Florida Current frontal eddies and the settlement of coral reef fishes. Limnol Oceanogr 50:1033-1048

Sponaugle S, Grorud-Colvert K, Pinkard D (2006) Temperature-mediated variation in early life history traits and recruitment success of the coral reef fish Thalassoma bifasciatum in the Florida Keys. Mar Ecol Prog Ser 308: $1-15$

Steneck RS, Paris CB, Arnold SN, Ablan-Lagman MC and others (2009) Thinking and managing outside the box: coalescing connectivity networks to build region-wide resilience in coral reef ecosystems. Coral Reefs 28: 367-378

Swearer SE (2001) Self-recruitment in coral-reef fish populations. PhD thesis, University of California, Santa Barbara, CA

Swearer SE, Caselle JE, Lea DW, Warner RR (1999) Larval retention and recruitment in an island population of a coral-reef fish. Nature 402:799-802

Szmant A (1986) Reproductive ecology of Caribbean reef corals. Coral Reefs 5:43-54

Szmant AM (1991) Sexual reproduction by the Caribbean reef corals Montastrea annularis and M. cavernosa. Mar Ecol Prog Ser 74:13-25

Szmant AM, Miller MW (2006) Settlement preferences and post-settlement mortality of laboratory cultured and settled larvae of the Caribbean hermatypic corals Montastraea faveolata and Acropora palmata in the Florida Keys, USA. Proc 10th Int Coral Reef Symp 49:43-49

> Szmant AM, Weil E, Miller MW, Colon DE (1997) Hybridization within the species complex of the scleractinan coral Montastraea annularis. Mar Biol 129:561-572

Treml EA, Halpin PN (2012) Marine population connectivity identifies ecological neighbors for conservation planning in the Coral Triangle. Conserv Lett 5:441-449

Treml EA, Halpin PN, Urban DL, Pratson LF (2008) Modeling population connectivity by ocean currents, a graphtheoretic approach for marine conservation. Landsc Ecol 23:19-36

> Vermeij MJA, Fogarty ND, Miller MW (2006) Pelagic conditions affect larval behavior, survival, and settlement patterns in the Caribbean coral Montastraea faveolata. Mar Ecol Prog Ser 310:119-128

> Victor BC (1986) Delayed metamorphosis with reduced larval growth in a coral reef fish. Can J Fish Aquat Sci 43: 1208-1213

> Vikebø F, Jørgensen C, Kristiansen T, Fiksen Ø (2007) Drift, growth, and survival of larval Northeast Arctic cod with simple rules of behaviour. Mar Ecol Prog Ser 347: 207-219

Vuilleumier S, Possingham HP (2006) Does colonization asymmetry matter in metapopulations? Proc R Soc Lond B Biol Sci 273:1637-1642 
Appendix 1. Larval vertical distributions were parameterized in the Connectivity Modeling System with vertical matrices. The format of these matrices is given in the key, followed by species-specific matrices and references

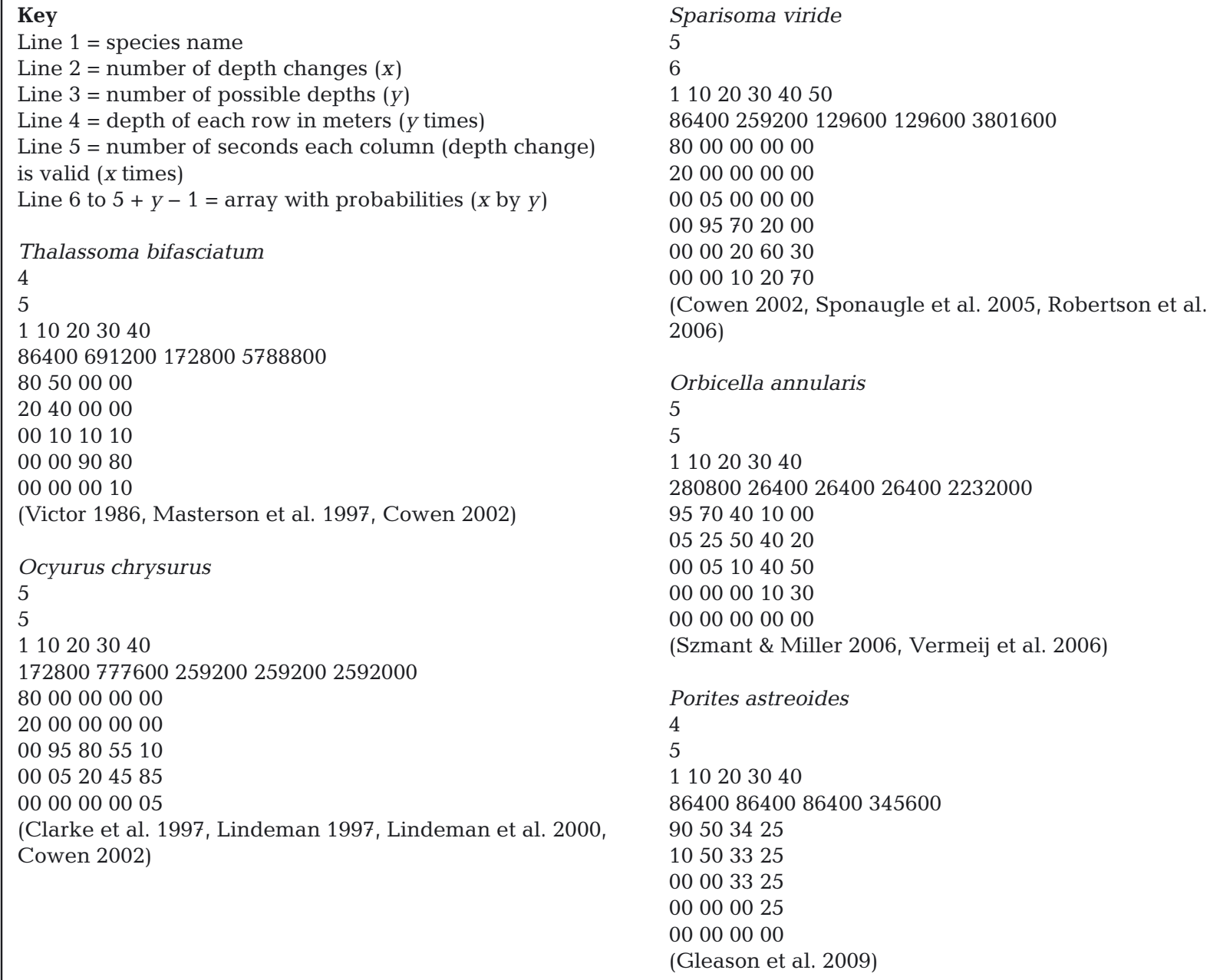

Editorial responsibility: Charles Birkeland, Honolulu, 